\title{
Innovative physical therapy practice: a qualitative verification of factors that support diffusion of innovation in outpatient physical therapy practice
}

This article was published in the following Dove Press journal:

Journal of Healthcare Leadership

I December 2016

Number of times this article has been viewed

\section{Carla Sabus' \\ Ellen Spake ${ }^{2}$}

'Department of Physical Therapy and Rehabilitation Science, University of Kansas Medical Center, Kansas City, $\mathrm{KS},{ }^{2}$ Rockhurst University, Kansas City, MO, USA
Correspondence: Carla Sabus Department of Physical Therapy and Rehabilitation Science, University of Kansas Medical Center, 390I Rainbow, MS 2002, Kansas City, KS 66160, USA Tel + I 9135886736

Email csabus@kumc.edu
Background and purpose: New ideas, methods, and technologies spread through cultures through typical patterns described by diffusion of innovation (DOI) theory. Professional cultures, including the physical therapy profession, have distinctive features and traditions that determine the adoption of practice innovation. The Consolidated Framework for Implementation Research (CFIR) proposes a framework of innovation implementation specific to health care services. While the CFIR has been applied to medical and nursing practice, it has not been extended to rehabilitation professions. The purpose of this qualitative study was to verify the CFIR factors in outpatient physical therapy practice.

Design: Through a nomination process of area rehabilitation managers and area directors of clinical education, 2 exemplar, outpatient, privately owned physical therapy clinics were identified as innovation practices. A total of 18 physical therapists (PTs), including 3 owners and a manager, participated in the study.

Methods: The 2 clinics served as case studies within a qualitative approach of directed content analysis. Data were collected through observation, spontaneous, unstructured questioning, workflow analysis, structured focus group sessions, and artifact analysis including clinical documents. Focus group data were transcribed. All the data were analyzed and coded among 4 investigators.

Results: Through data analysis and alignment with literature in DOI theory in health care practice, the factors that determine innovation adoption were verified. The phenomena of implementation in PT practice are largely consistent with models of implementation in health care service. Within the outpatient practices studied, patient-centered care and collaborative learning were foundational elements to diffusion of an innovation.

Conclusion: Innovation in outpatient physical therapy practice can be understood as a social process situated within the culture of the physical therapy professional that follows predictable patterns that strongly align with DOI theory and the CFIR.

Keywords: innovation, organizational change, professional development, evidence-based practice

\section{Introduction}

Health care practice continually changes. The move to electronic health records, the expectation that practice patterns align with evidence, consumer demands, practice competition, and delivery of cost-effective care that results in noticeable outcomes require all health care providers to be highly adaptive. Innovation opportunities are being introduced exponentially in our society and in health care practice; however, research consistently reveals the stubborn nature of health care practice patterns that 
are slow to integrate research findings. ${ }^{1,2}$ Rehabilitation professionals such as physical therapists (PTs), occupational therapists, and speech-language pathologist have defined the scope of practices and exist within distinct practice environments. Each profession also exists within its own professional norms and communities of practice that present unique factors that interface with innovation uptake. This study tests 2 conceptual frameworks of health care innovation in physical therapy practice.

Evidence-based practice (EBP) is just one driving catalyst for practice innovation. EBP was introduced as a set of individual, behavioral steps involving obtaining, critiquing, and implementing research findings. Approximately 20 years since its introduction, EBP approaches adulthood with emphasis on the translation of clinical evidence to the clinical environment. Innovation in PT practice may also stem from advanced skills and knowledge associated with the growing trend toward practice specialization. In addition, the current reimbursement climate is challenging PTs to stay abreast with documentation and billing requirements and consider novel models in delivering care within payment constraints. Consumer preferences and collaborative care with an interprofessional team also change the practice dynamics. The physical therapy profession identifies with traditional health care models, but outpatient practices are challenged to compete with alterative health care options in the community including chiropractic care, massage therapy, and general fitness services.

Health care research accepts that clinical innovation is a highly social process. Diffusion of innovation (DOI) theory has been complemented with social and organizational theory to build conceptual frameworks of health care innovation. The core elements of DOI theory have been translated to health care primarily through the study of medical and nursing practice..$^{3-5}$ While research in innovation uptake and knowledge translation in medical and nursing practice may largely translate to rehabilitation professions, established conceptual frameworks derived in medical practice have not been tested in rehabilitation contexts, specifically physical therapy practice. Verification of the elements of diffusion that determine whether necessary innovations will have successful uptake is of particular interest to organizations that invest scarce resources to quality improvement and professional staff development.

The specific aim of this qualitative study was to verify and describe the DOI factors within the context of outpatient physical therapy practice.

\section{Background and significance}

Recognizing that the PT rarely practices in isolation, innovation can be best understood as a group process. West and Altink $^{6}$ offer the socially informed definition of innovation: "the intentional introduction and application within a role, group, or organization, of ideas, processes, products, or procedures, new to the relevant unit of adoption, designed to significantly benefit the individual, the group, or wider society." This definition captures the elements of innovations relevant to PT practice. An innovation would be new, would involve a process of uptake, and would be accepted and sustained based on the appreciable benefit.

The adoption of innovation has been described in DOI theory that has been validated in countless studies over the past half century. The applicability of DOI theory has been investigated in health care delivery, namely in the effective update of electronic health records and EBP guidelines that improve patient safety. ${ }^{7}$ Health care introduces unique innovation characteristics that raise the threshold of uptake in comparison to social innovations such as adoption of mobile technology or the latest fashion trend. Health care innovation models that apply organizational theory and innovation theory to the culture of health services have been described. ${ }^{4,8-13}$ These health care models incorporate unique triggers that prompt innovation and system-level adoption elements that operate within a context of patient-centered care.

\section{DOI theories}

This research extends concepts that were the pioneering work of Rogers' DOI theory. ${ }^{14}$ The theory has roots in agricultural diffusion and has been applied to numerous examples of successful DOI including cell phone use, birth control, seat belt use, as well as notable failures of others, such as electric cars and US conversion to the metric system. Rogers' theory has evolved over the last half century, but basic tenets provide a stable and valid framework for the analysis of innovation uptake. Key elements of diffusion involve the innovation, "an idea, practice, or object that is perceived as new by an individual or other unit" that is communicated through certain channels, over time among members of a social system. ${ }^{14}$

The characteristics of the innovation itself influence its diffusion. An innovation that is compatible and advantageous to current conditions is more likely to be implemented. Furthermore, the degree that individuals can experiment, adapt, or modify the innovation supports diffusion. This contextual morphing of the innovation is termed reinvention. Innovation acceptance is more likely if benefits are directly 
observable and attributable to the innovation. An innovation is more likely to have sustained adoption if adopters perceive an appreciable gap between the innovation's disruption or inconvenience and the innovation's benefit.

An innovation spreads among individuals or groups through communication channels. Typically, the innovation is introduced by an innovator, who may be on the edges of social group. The innovator has more exposure to external contacts and innovation sources. Rather than peer pressure, the innovator is typically persuaded by objective and scientific rationale. The innovator's spread of the innovation to his/her social group is mediated by a change agent. The effective change agent has high acceptance and commonality to a social group, uses peer persuasion, and maintains credibility and influence through a reputation of prudence, advancing advantageous innovations and slowing undesirable innovations.

Rogers classifies individuals within the diffusion process: innovators, early adaptors, early majority, late majority, and laggards; however, social interdependence is an important determinant of adoption. The social system and environment may strongly influence the rate and success of innovation uptake. Diffusion is highly dependent on the innovation's perceived compatibility to the group norm. An innovation that is incompatible with group norms and culture will likely be rejected even if it is clearly advantageous.

The environmental conditions, both external and internal to the group, influence innovation adoption rate and success. A group's organizational structure, climate and culture, leadership, and history impact implementation. Adoption often requires resource allocation, and an innovation's implementation must be prioritized.

\section{DOI theory in health care}

Unlike community and social innovations that benefit from "epidemic spread" 15 and are precipitated by peer pressure and cosmopolitan qualities, health care innovations are motivated by distinct factors. Health care does not hold a presumption that new is better; health care innovations must be vetted by evidence and experts and may unseat a standard of care that is an established "gold standard". Health care delivery is multifaceted; health care innovations often consist of a "hard core" (key, set elements of the innovation) and "fuzzy boundaries" (negotiable and contextual elements of innovation). ${ }^{13}$ An innovation must be communicated through credible channels and must be substantiated by research, a more rational, but socially dependent method. Health care innovation uptake could be motivated by regulation adherence or a sociopolitical basis to establish competitive edge. ${ }^{4}$ Within health care, team functioning is critical for innovation success, and team dynamics tend to follow traditional lines of role delineation and power structure. The team's shared vision, participation, and task orientation are particularly imperative through the adoption process. While the innovation itself may be communicated to individuals, implementation is a social process. ${ }^{16}$

Physician practice research reveals the importance of matching an innovation to the priorities, motivations, and conditions within the organization. Predictive factors of an innovative organization include shared vision among group members, clearly communicated vision from leadership, flexibility and compatibility of the innovation with current practice, and community resources. ${ }^{17}$ Physician practice research specifically addressing adherence to EBP guidelines reveals recurring themes: it is difficult to change practice behavior, and practice behavior occurs within a highly influential social context. ${ }^{18-21}$

Implementation science, the translation of evidence or knowledge to practice, is essentially the study of innovation adoption. Research discoveries are often not integrated into clinical practice or suffer from significantly delayed introduction. ${ }^{1}$ Clinical innovation suffers from a slower rate of adoption than social phenomena and has been proposed to be the least efficient sector in innovation adoption..$^{22}$ To understand and describe health care innovation, DOI theory has been complemented with organizational, complexity theory, and behavioral and social theories to build frameworks specific to health care. Adoption of innovation in health care has been widely accepted as a complex, organizational process that is much more humanistic than mechanistic. ${ }^{23-27}$

Greenhalgh and Robert ${ }^{13}$ developed a conceptual model of DOI specific to health service organizations. This conceptual model of organizational diffusion extends Rogers' ${ }^{14}$ theory that uses the individual as the unit of analysis of a product-based innovation. This conceptual model acknowledges that the organizational knowledge dictating health care practice is socially constructed. Uptake of any health care innovation requires more than transfer of information to an individual; information must be integrated into shared social knowledge and shared understanding that are consistent with organizational norms and values. Greenhalgh and Robert draws a distinction between diffusion, the passive spread of an innovation, and dissemination, the active and planned efforts to targeted groups or individuals. Implementation is the active, planned effort to routinize an innovation within an organization. Sustainability refers to the establishment of an 
innovation that withstands challenge or reversal. Greenhalgh and Robert's conceptual model depicts interplay between the innovation, the organizational context, its members, and external influence. This model conveys cyclical adoption of innovation that contrasts with Roger's DOI linear process.

The Consolidated Framework for Implementation Research (CFIR) was derived through a meta-narrative approach that aligned findings across the implementation theory of health care services to organize a framework using defined, distinct constructs with consistent terminology. The CFIR extends Greenhalgh and Robert's work in an effort to guide theory development for verification in the varied health care service settings. The CFIR includes detailed construct definitions and rationale to guide extension of the implementation research in health care. Paralleling Roger's DOI elements, the CFIR includes 26 constructs that are categorized within 5 domains: intervention characteristics, outer setting (external influence), inner setting (internal factors), characteristics of individuals, and the process. ${ }^{23}$

Innovation factors within health care organizations have been described, but the literature cautions that the adoption process is highly contextual, warranting setting- and profession-specific study. ${ }^{13}$ Physical therapy professionals and physical therapy practice have distinct attributes. Physical therapy practice may follow proposed models of DOI and mirror the CFIR, but it is expected that some aspects of adoption are situated in the delivery of care that is distinct to physical therapy practice. This study verifies the level of alignment of the CFIR constructs and definitions to physical therapy practice. It is not the intent to derive original constructs and definitions to physical therapy practice, rather, verification of the alignment with the established CFIR framework will support and direct future research.

\section{Methods}

Study sites and participants were based on qualitative, purposive sampling seeking information-rich cases that exemplify the construct, innovative practice. Clinics that exemplify innovative, EBP were identified through electronic balloting of members of the Kansas City Area Rehabilitation Management group and representatives from the 2 local Doctor of Physical Therapy (DPT) programs: 2 program chairs and 2 directors of clinical education. Qualitative sampling through nomination by professional leaders has been successfully applied in previous physical therapy research. ${ }^{1}$

The Agency of Health Care Research and Quality (AHRQ) offers a detailed description of health care innovation directed toward the range of practice of behavior of individuals to organizational entities. The AHRQ comprehensive description incorporates the institutes of medicine quality domains - effectiveness, efficiency, equity, patient centeredness, safety, and timeliness. ${ }^{28}$ Based on the AHRQ, a succinct operational definition of the innovative physical therapy practice was derived.

An innovative, evidence-based physical therapy practice provides patient-centered care that is responsive to discovery and emerging evidence to achieve highest outcomes. The clinic's professional staff is recognized by the professional community for their level of professional engagement, research, education, and/or leadership.

Clinic inclusion criteria were location within a 50-mile radius of the Kansas City metropolitan area, independent outpatient PT practice, and employment of at least 4 fulltime equivalent PTs. Physician-owned practices, hospitalor corporate-affiliated outpatient clinics, and practices in existence $<2$ years were excluded.

Once identified, written consent from the clinical staff and administrative approval was obtained. Clinical staff were notified of the study through on-site meetings explaining the study purpose and research methods. Focus group participation was limited to only consenting participants. Direct patient observation was subject to waiver of consent through posted notifications within the clinic.

Two investigators observed each clinic's usual workflow that included delivery of services, staff interactions, staff meetings, and an in-service. Clinical documents were collected as artifacts: job descriptions, performance review templates, marketing materials, patient education handouts, and strategic planning and mission statement documents. Photos of the clinic environment were captured. Participants self-evaluated personal and clinic propensity toward innovation adoption by identifying perceived position on the DOI Time X Adoption Innovation Curve (Figure S1). Participants were instructed to mark on the Time X Adoption Curve, an " $\mathrm{X}$ " on the personal tendency and an "O" on the clinic's tendency toward innovation uptake.

Interview questions were developed after investigator observation and analysis of artifacts. Two rounds of focus group sessions were held with groups of 2-7 staff PTs. Manager/owner sessions were conducted separately. Figure 1 summarizes the chronology of the study design.

The following qualitative strategies was applied to ensure credibility and transferability of the proposed study: 1) triangulation, multiple modalities of data sources (interview, observation, images, record audit), 2) theoretical, purposive sampling to supply rich presentation of the construct of 


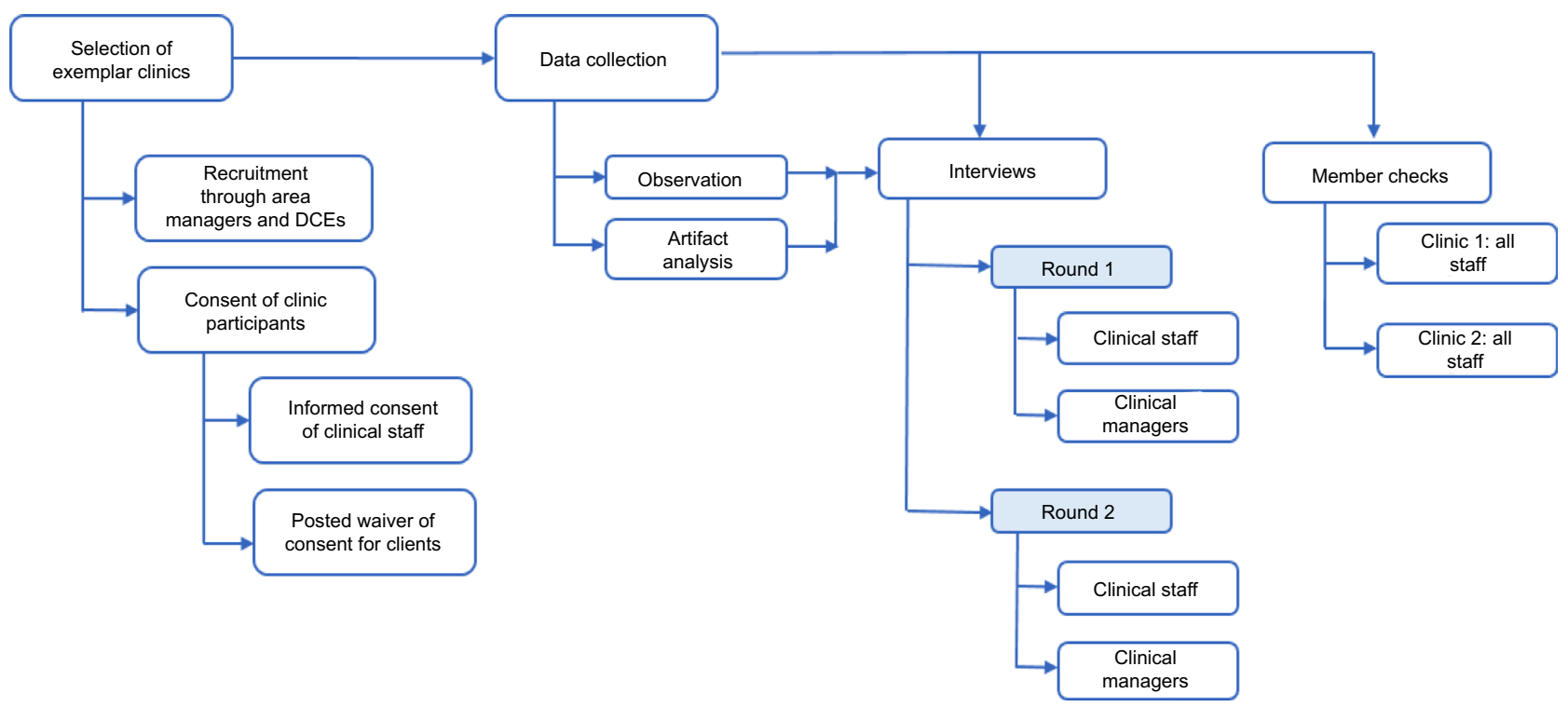

Figure I Chronology of the study design.

Abbreviation: DCE, Director of Clinical Education.

interest, 3) multiple investigators and analysts, and 4) member checks for the accuracy of findings. ${ }^{29,30}$

The study and research methods were approved by the Institutional Review Board of the University of Kansas Medical Center.

\section{Qualitative data analysis}

Investigators applied a directed content analysis approach to data analysis, a structured process of verification of factors and their operational definitions within the PT practice context. ${ }^{31}$ Nvivo 9 (QSR International Pty Ltd, Burlington, MA, USA) was used to archive and organize multiple data sources and analysis. Coding was performed on Nvivo 9 and in Word and Excel (Microsoft Corporation, Redmond, WA, USA) documents.

All focus group sessions were audio recorded and transcribed. All data, photos, and transcripts were subjected to opening coding. Four investigators independently developed preliminary broad categories following the first focus group sessions. Comparing these codes across investigators informed the development of the second focus group questions. The second focus group session concentrated on undeveloped and discrepant themes. Codes were refined based on the second focus group session data into axial codes, representing categories within the data. Through analysis and investigator agreement, codes were condensed to themes.

The agreement of the implementation factors between the CFIR and the PT practices was evaluated within the 5 domains: innovation (intervention) characteristics, characteristics of individuals, inner setting, outer setting, and process characteristics. Detailed CFIR ${ }^{23}$ and parallel Greenhalgh and Robert's ${ }^{13}$ definitions and rationale for constructs were referenced in the analysis process. To evaluate alignment to the CFIR, the CFIR constructs that did not emerge through data collection were designated as neutral $(\mathrm{N})$. Through the process of independent coding among investigators followed by discussion to reach agreement, constructs that emerged within the first-round analysis were designated as + . The second round of data collection and analysis was structured to provide additional verification, clarification, and confirmation or disconfirmation of factors. Following the second round of independent data analysis among investigators followed by discussion to reach agreement, those constructs that were retained but did not reach strong confirmation were designated as + , and those constructs with strong and verified support through second round data collection were designated as ++ .

Findings were summarized and presented to study participants to seek refinement and to verify findings. Participant surveys were used during the member check sessions to support theme verification and allow feedback from all participants who may have been reluctant to voice input in the full group meeting (Table S1). No adjustment to codes, themes, or results was necessary following the member checks.

\section{Results}

Two clinics participated in the study. Clinic 1 consisted of the owner, a manager, and 12 PTs at the time of the study onset; the 11 PTs available during the study duration, the owner, and the manager participated in the study. Clinic 2 included 2 owners and 3 PTs who all participated in the study. The experience of clinicians ranged from $<3$ years to $>35$ years. 
Neither clinic employed physical therapist assistants. The majority of PTs had a DPT and all had obtained or were in the process of obtaining some level of specialty certification.

Both clinics were transitioning in the adoption of operational and workflow responses to reimbursement changes and outcome reporting. For one of the clinics, innovation was dominated by patient-reported outcome measures that redefined billing, patient evaluation, patient plan of care, and marketing. During the 15-month course of the study, 1 clinic had just implemented significant PT pay restructuring and was investigating potential for a cash-based business.

While the CFIR refers to an intervention as the source of innovation, within these clinics, change was more multifaceted than a specific intervention. Both clinics were experiencing change that was operational, and in 1 clinic this involved adjustment to the practice model. Therefore, this study applies the term "innovation", rather than the more specific CFIR term "intervention". Considering the distinction between diffusion as a passive spread of an innovation and dissemination as an active, planned implementation of innovation, the deliberate innovations observed through the course of this study would be most accurately characterized as dissemination.

\section{Innovation characteristics}

Table 1 presents the level of agreement in the innovation characteristics between the CFIR and PT practice. Detailed definitions of CFIR innovation constructs are provided.

The innovation characteristics such as potential for reinvention or modifying the innovation, observable benefit, low level of complexity, and ease of understanding, all support innovation adoption. PTs expressed the cautious evaluation of an innovation that is consistent with health care service that relies on quality evidence rather than novelty alone.
I am typically an early researcher, or if I see something on the horizon with promise, I'm going to go for it [...], but it is not just like jumping in, it has to be researched.

For many of the PTs who held a strong conviction in the quality in their practice, innovation required a level of necessity, particularly if the innovation threatened essential practice attributes. The presentation of the innovation to the organization members must acknowledge the core practice philosophy and values. Members largely agreed that while innovation was negotiable and subject to reinvention, practice values had to be retained.

We have tried to be innovative to try to continue our model of care by trying to get more of a cash-based business and a lot of people have really tried hard to get more of that concept...we can be a successful business and continue to work together toward all of our goals of making the patient better.

The tolerance for reinvention and tailored implementation showed strong relevance particularly for the implementation of novel patient interventions. The PTs described the interplay between reinvention and reflective practice through the implementation process. The PT staff identified the importance of strong mentoring coupled with personally tailoring the innovation through reinvention and experimentation.

We are both learning together... here it's a main focus for the practice. I'm always asking questions...If I'm ever in doubt, just getting that reassurance from [the owners], reviewing a technique gives me extra confidence.

You borrow from the advanced clinicians, and they've come up with something that you are not going to find documented anywhere but just works, and then I will find myself doing it as well. [participant]

Table I The innovation

\begin{tabular}{|c|c|c|}
\hline CFIR constructs & $\begin{array}{l}\text { Level of } \\
\text { agreement }\end{array}$ & CFIR definition ${ }^{23}$ \\
\hline Innovation source & $\mathrm{N}$ & $\begin{array}{l}\text { Perception by the members of the organization about whether the innovation is externally or } \\
\text { internally developed }\end{array}$ \\
\hline Evidence strength and quality & $\mathrm{N}$ & $\begin{array}{l}\text { Organization members' perceptions of the quality and reliability of the evidence that the } \\
\text { innovation will produce the desired outcomes }\end{array}$ \\
\hline Relative advantage (observability) & + & Organization members' belief in the advantage of the innovation as an alternative to the status quo \\
\hline Adaptability (reinvention) & + & The degree that the innovation can be adjusted to improve fit to the organization \\
\hline Trialability & ++ & The degree that the innovation can be trialed or implemented in smaller scale or steps \\
\hline Complexity & + & $\begin{array}{l}\text { The degree of difficulty that the innovation entails including the number of steps and the number } \\
\text { of choices that the innovation involves }\end{array}$ \\
\hline Design quality and packaging & + & Effectiveness of the presentation of the innovation to organization members \\
\hline Cost & $\mathrm{N}$ & $\begin{array}{l}\text { Resources required for innovation implementation including money, time, training, and } \\
\text { productivity risks }\end{array}$ \\
\hline
\end{tabular}

Notes: +, agreement; ++, strong agreement; N, neutral/not confirmed. Adapted from Damschroder L, Aron D, Keith RE, Kirsh SR, Alexander JA, Lowery JC. Fostering implementation of health services research findings into practice: a consolidated framework for advancing implementation science. Implement Sci. 2009;4(I):50. ${ }^{23}$ Abbreviation: CFIR, Consolidated Framework for Implementation Research. 


\section{Characteristics of individuals}

Table 2 presents the level of agreement in characteristic of individual constructs between the CFIR and PT practice.

Detailed definitions of CFIR characteristics of individual constructs are provided.

Individuals have varied acceptance of innovation that is mediated by the individual's perceptions of the innovation and its compatibility with personal values, the individual's confidence in the ability to implement the innovation, and personal propensity toward change and acceptance of risk. To the extent that innovation represents the organization's priorities, each individual also uses the innovation to gage the alignment that he/she has with the organization. For these small practices, alignment also entailed the level of personal investment and ownership in the clinic success that an individual accepted. Various personal motivators disposed the individual toward acceptance or rejection of particular innovation. For example, an individual's career opportunities may present or could be threatened by an innovation.

I don't take [the innovation] as a personal attack ... so

I almost feel like a pioneer; I'm excited about it. Let's figure this out. I just feel that it's more of an opportunity. It's scary...

So it's a lot of risk tolerance and personal, financial stability that will dictate what this practice looks like.

Table 2 Characteristics of individuals

\begin{tabular}{|c|c|c|}
\hline CFIR constructs & $\begin{array}{l}\text { Level of } \\
\text { alignment }\end{array}$ & CFIR definition ${ }^{23}$ \\
\hline $\begin{array}{l}\text { Knowledge and } \\
\text { beliefs about the } \\
\text { innovation }\end{array}$ & + & $\begin{array}{l}\text { Attitudes and understanding } \\
\text { of the innovation, in particular, } \\
\text { command of the knowledge and } \\
\text { skills the innovation requires }\end{array}$ \\
\hline Self-efficacy & ++ & $\begin{array}{l}\text { Belief in capability to be successful } \\
\text { in implementation steps }\end{array}$ \\
\hline $\begin{array}{l}\text { Individual stage of } \\
\text { change }\end{array}$ & + & $\begin{array}{l}\text { Phase of the innovation use } \\
\text { by the individual ranging from } \\
\text { awareness, decision to change, } \\
\text { adoption, confirmation; individual } \\
\text { orientation to acceptance of } \\
\text { change }\end{array}$ \\
\hline $\begin{array}{l}\text { Individual } \\
\text { identification with } \\
\text { organization }\end{array}$ & ++ & $\begin{array}{l}\text { Perceived relationship, alignment } \\
\text { and level of commitment to the } \\
\text { organization }\end{array}$ \\
\hline $\begin{array}{l}\text { Other personal } \\
\text { attributes }\end{array}$ & ++ & $\begin{array}{l}\text { Other characteristics of } \\
\text { individuals in the specific } \\
\text { organizational context including } \\
\text { career aspirations }\end{array}$ \\
\hline
\end{tabular}

Notes: Bold text indicates expanded definition. +, agreement; ++, strong agreement. Adapted from Damschroder L, Aron D, Keith RE, Kirsh SR, Alexander JA, Lowery JC. Fostering implementation of health services research findings into practice: a consolidated framework for advancing implementation science. Implement Sci. 2009;4(I):50.23

Abbreviation: CFIR, Consolidated Framework for Implementation Research.
The tolerance of risk appeared to correspond with the individual PT's alignment with the clinic's inclination toward innovation adoption. Participant responses on DOI Time X Adoption Curve were reduced to frequency within categories: innovator, early adopter, early majority, late majority, and late adopter. Figure 2 depicts the frequency distributions of the PT and clinic. Aggregate frequencies between the clinics revealed that the majority of PTs fell in the early majority category. The clinic adoption was perceived with nearly equal distribution across innovator, early majority, and late majority. The PTs were nearly equally split in qualifying faster or slower adoption in comparison to the clinic. Collectively, the PT staff were highly homogenous in their reported acceptance of innovation which reinforces the concept of shared acceptance of a culture of innovation and tolerance of uncertainty of an innovative environment. While sample size is not sufficient for a conclusive interpretation, the trend suggests that the clinics had higher propensity toward adoption than individuals. Aligning these results to qualitative themes appears to reinforce the highly social nature of adoption; an individual with normative adoption tendencies may demonstrate increased rate of adoption within a more progressive environment. Furthermore, an innovative clinic may not be simply a collection of innovative individuals but dependent on a collective culture that supports innovation and risk.

\section{Inner setting}

Table 3 presents the level of agreement in inner setting constructs between the CFIR and PT practice. Detailed definitions of CFIR inner setting constructs are provided.

The level of innovation within a practice can be considered a "core property" of the practice identity and embedded in the clinical culture. Collectively, the PTs conveyed a sense that the practice was an exception to typical, routine practice. A climate of continuous learning, investing in continuing

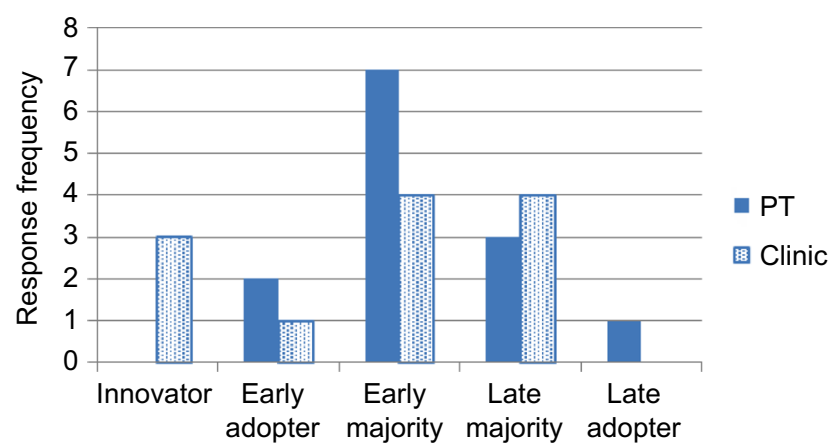

Figure 2 Distribution of self-identified adoption. Abbreviation: PT, physical therapist. 
Table 3 The inner setting

\begin{tabular}{|c|c|c|}
\hline CFIR constructs & $\begin{array}{l}\text { Level of } \\
\text { alignment }\end{array}$ & CFIR definition ${ }^{23}$ \\
\hline Structural characteristics & $\mathrm{N}$ & The organization's size, age, and level of differentiation \\
\hline Networks and communications & ++ & $\begin{array}{l}\text { The nature and quality of information and formal communications and effectiveness of } \\
\text { networks to convey information }\end{array}$ \\
\hline Culture & ++ & Values, norms, traditions, and assumptions within an organization \\
\hline $\begin{array}{l}\text { Implementation climate (absorptive } \\
\text { capacity for new knowledge) }\end{array}$ & & $\begin{array}{l}\text { The level of receptivity of innovation among organization members and the degree that } \\
\text { innovation within the organization is expected and rewarded }\end{array}$ \\
\hline Tension for change & + & $\begin{array}{l}\text { The degree that members find the innovation necessary and perceive the alternative, status } \\
\text { quo, as untenable }\end{array}$ \\
\hline Compatibility & ++ & $\begin{array}{l}\text { The innovation's alignment with the organization's values and established systems and } \\
\text { workflow }\end{array}$ \\
\hline Relative priority & $N$ & $\begin{array}{l}\text { Organization members' shared perception of the importance of innovation. Negative } \\
\text { effect of cumulative changes }\end{array}$ \\
\hline $\begin{array}{l}\text { Organizational incentives and } \\
\text { rewards }\end{array}$ & $N$ & $\begin{array}{l}\text { Tangible - raises, promotion, and award, and intangible - prestige, status, gained by } \\
\text { members who adopt the innovation. } \\
\text { Conversely, the impact of potential disincentives or penalty/loss for members or } \\
\text { organizations who fail in implementation }\end{array}$ \\
\hline Goals and feedback & + & $\begin{array}{l}\text { The extent that the objectives of the innovation are communicated and that implementation } \\
\text { feedback aligns with stated goals. Need for small steps. Incremental, specific, } \\
\text { attainable steps coupled with leadership commitment }\end{array}$ \\
\hline Learning climate & ++ & $\begin{array}{l}\text { The organization's attributes to support learning, including a) leaders who express fallibility; } \\
\text { b) collective efforts valued; c) psychological safety among members; d) time to make/share } \\
\text { meaning through reflection; e) members who are not constrained by failure. Learning in } \\
\text { organization is a "core property" }\end{array}$ \\
\hline $\begin{array}{l}\text { Readiness for implementation: } \\
\text { (receptive context for change) }\end{array}$ & & $\begin{array}{l}\text { Tangible and specific indicators of the organization's commitment to implement an } \\
\text { innovation }\end{array}$ \\
\hline Leadership engagement & ++ & Commitment, involvement, and accountability of the organization's leaders and managers \\
\hline Available resources & $N$ & $\begin{array}{l}\text { Resources dedicated to successful implementation of an innovation, money, time, training, } \\
\text { and space. Resources serve as mediator or proxy of management support }\end{array}$ \\
\hline $\begin{array}{l}\text { Access to knowledge and } \\
\text { information }\end{array}$ & + & $\begin{array}{l}\text { Members' access to and ease of understanding information about the innovation and its } \\
\text { implementation }\end{array}$ \\
\hline
\end{tabular}

Notes: Bold text indicates expanded definition. +, agreement; ++, strong agreement; N, neutral/not confirmed. Adapted from Damschroder L, Aron D, Keith RE, Kirsh SR, Alexander JA, Lowery JC. Fostering implementation of health services research findings into practice: a consolidated framework for advancing implementation science. Implement Sci. 2009;4(I):50. ${ }^{23}$

Abbreviation: CFIR, Consolidated Framework for Implementation Research.

education, and challenging practice was a practice goal of the clinic owners and a strong incentive for the PTs who chose the clinic over competitive employment offers.

Innovation and the disruption that it entails must be accepted within the organization as the price of being a competitive and progressive practice. Practices that value innovation and successfully implement innovation must have internally supportive elements. Within these independent private practices, organizational culture and a learning climate mediated by effective networks of communication emerged as important elements. Implementation is supported by an organizational culture that allows risk taking and negotiated meaning among its members. While members may have diverse backgrounds and practice interests, an innovation's meaning is conveyed through shared language and accepted clinic norms.

I do not feel like I am just an employee. It feels like we are part of a very unified team.
Even though we learn a lot of the same techniques, there is not a pressure that we have to use that technique but at least we all know the language and so we understand.

I want to reemphasize that it's not so strictly prescribed that we have to do it exactly the same way. But having a lot of similar approaches when we practice things together, we talk the same language to each other.

Innovation alignment to organization mission was a predominant theme within the data. For each clinic, opportunities for innovation were evaluated against compatibility with organizational mission and values. A perception that the innovation drifts from the clinic's core values was particularly detrimental to acceptance of an innovation. Implementation must be articulated with clear vision and purpose.

We really wanted to focus on providing skilled care for every minute the patient is getting their one-on-one care. So we envisioned 45 minutes for each patient that they're with the PT. 
...fundamental value is, you've got to care about patients.

Strong leadership and effective relationships between managers and staff are required in the workplace and through implementation. Management must present innovation and planned implementation with a level of transparency and with necessary background information to build the compelling case for change. Through implementation, management uses reliable means of data capture as a source of feedback to staff.

We get their input. We try to run this clinic as if we're employees as well and they're owners as well. We give each PT the opportunity to buy in.

I believe very much in open-book management so we literally post every single month how much we billed, collected and net profitability. We're very open about almost everything.

\section{Outer setting}

Table 4 presents the level of agreement in outer setting constructs between the CFIR and PT practice. Detailed definitions of CFIR outer setting constructs are provided.

The innovations during the time of this study were largely precipitated by the external climate, namely shrinking reimbursement and billing requirements that demanded response. For both clinics, the range of responses was reduced to options that preserved patient-centered care and that situated the clinic for sustainable competitive advantage.

We provide amazing patient care and we make that the very first thing we do. We create genuine care and connection with patients. Everything else will fall into place, no matter how we do things. I still firmly believe that.

The tolerance of risk or alienation from normative community practice that is associated with innovative was accepted by organization members as a mark of identity and quality.

I felt like there is a certain swagger and standard in the clinic. I feel that it accepts a challenge, looks forward to a challenge... but in the same way, holds itself to higher standards.

\section{The process}

Table 5 presents the level of agreement in process between the CFIR and PT practice. Detailed definitions of CFIR process constructs are provided.

Table 4 The outer setting

\begin{tabular}{|c|c|c|}
\hline CFIR constructs & $\begin{array}{l}\text { Level of } \\
\text { alignment }\end{array}$ & CFIR definition ${ }^{23}$ \\
\hline $\begin{array}{l}\text { Patient's needs } \\
\text { and resources }\end{array}$ & ++ & $\begin{array}{l}\text { The extent that the organization's } \\
\text { ability to meet its patients' needs } \\
\text { is understood and valued by the } \\
\text { organization's members }\end{array}$ \\
\hline Cosmopolitanism & + & $\begin{array}{l}\text { The extent of the organization's } \\
\text { networks to external influences and } \\
\text { competing organizations }\end{array}$ \\
\hline Peer pressure & $\mathrm{N}$ & $\begin{array}{l}\text { The level of innovation modeled } \\
\text { by organization peers that compels } \\
\text { imitation or improvement }\end{array}$ \\
\hline $\begin{array}{l}\text { External policies } \\
\text { and incentives }\end{array}$ & ++ & $\begin{array}{l}\text { Requirements, regulations, } \\
\text { opportunities, or threats originating } \\
\text { outside the organization that } \\
\text { require reaction }\end{array}$ \\
\hline
\end{tabular}

Notes: +, agreement; ++, strong agreement; $\mathrm{N}$, neutral/not confirmed. Adapted from Damschroder L, Aron D, Keith RE, Kirsh SR, Alexander JA, Lowery JC. Fostering implementation of health services research findings into practice: a consolidated framework for advancing implementation science. Implement Sci. 2009;4(I):50. ${ }^{23}$ Abbreviation: CFIR, Consolidated Framework for Implementation Research.

Table 5 The process

\begin{tabular}{|c|c|c|}
\hline CFIR constructs & $\begin{array}{l}\text { Level of } \\
\text { alignment }\end{array}$ & CFIR definition ${ }^{23}$ \\
\hline Planning & + & The level and quality of preparation for the implementation of an innovation \\
\hline Engaging & & $\begin{array}{l}\text { Deliberate strategies including education, modeling, and training, to involve organization } \\
\text { members in the implementation of an innovation }\end{array}$ \\
\hline Opinion leader & ++ & $\begin{array}{l}\text { Respected member within an organization who is influential in changing attitudes and behaviors. } \\
\text { Integrity and prudence, attentive to group norms and builds credibility by evaluating } \\
\text { innovation against norms }\end{array}$ \\
\hline $\begin{array}{l}\text { Formally appointed internal } \\
\text { implementation leaders }\end{array}$ & $\mathrm{N}$ & Individual appointed to implement an innovation \\
\hline Champions & $\mathrm{N}$ & Individual who is dedicated to the innovation by advocating for success and challenging resistance \\
\hline External change agents & + & Individual outside the organization who influences or facilitates the innovation implementation \\
\hline Executing & + & Completing the planned implementation \\
\hline Reflecting and evaluating & ++ & Use of feedback to appraise the level and quality of the innovation implementation \\
\hline
\end{tabular}

Notes: Bold text indicates expanded definition. +, agreement; ++, strong agreement; N, neutral/not confirmed. Adapted from Damschroder L, Aron D, Keith RE, Kirsh SR, Alexander JA, Lowery JC. Fostering implementation of health services research findings into practice: a consolidated framework for advancing implementation science. Implement Sci. 2009;4(I):50. ${ }^{23}$

Abbreviation: CFIR, Consolidated Framework for Implementation Research. 
The implementation process is highly contextual to the innovation itself and the organizational setting. While the inner context primes the organization for the implementation readiness, innovation can be understood as an ongoing process of organizational capacity building. This process relies on feedback systems, member reflection, and ongoing member engagement in practice improvement.

Engaging organization members, or the process of winning the support of the members, is essential in moving members from innovation knowledge to implementation action. At the organizational level, the innovation is introduced and its meaning is transmitted and negotiated through established communication networks. The structure of communication networks described across numerous sources was verified in this study ${ }^{13,14}$ The innovator who detects the innovation and introduces the organization to the concept is socially positioned for innovation exposure from external sources. In this study, those sources were advanced training and professional resources. Due to higher risk tolerance and strong external ties, the innovator may suffer limited direct influence within the organization's social network. The innovator relies on a change agent who has multiple, strong connections within the organization. Change agents gain group credibility through attention to innovation alignment with the organization's values and culture and a tempered approach to implementation. ${ }^{13}$ Particularly, within the larger clinic, information was introduced through formal communication with the innovator; however, meaning was gained through informal peer networking facilitated with close contact with a change agent who is more homogeneous to the PT staff.

[Manager] talked about three different things last week..., so you've just got to try to go one step at a time and still try to keep a little bit more task oriented on the small details. He's the big picture guy. So it's not necessarily we don't agree with the ideas, it's just slowing things down. We're going to have to put a few things on hold that I think he's wanting to do that might actually cost more money right now, kind of put those a little bit and try to prioritize things.

While innovation is typically described as a hierarchical flow of information introduced to a social group by the innovator, in this study, participants conveyed that innovation flows in both directions. Innovation inspired by external sources was introduced by the innovator, but innovation that was organic to clinic and its patients' needs was also cultivated from within the clinic staff.

I think it goes to that ownership model too because people have come to us and said 'we want to do this [program]' and it always sounds great, ... until we put pen to paper and see what that looks like, .... It forces people to think through not only the logistics of it, but also the financials of it and when it would take place and how it would look.

In particular, uptake of continuing education content originated within the clinic staff. Participants strongly valued continuing education and cited it as a strong source of innovation. This contrasts with studies that have found that continuing education suffers limited clinical impact. ${ }^{32,33}$ Barriers to integration of continuing education content have not been well described, but these findings suggest that the reciprocal exchange of continuing education content between group members and group leaders may be a decisive factor.

\section{Discussion}

Innovation is disruptive; innovation in itself cannot be assumed to be positively perceived by organization members. ${ }^{12}$ But PTs largely accept that it is a professional responsibility to shift practice patterns and adapt to a dynamic health care service climate. The propensity for an organization to be innovative and to support its individual members in adaptability may be associated with alignment to established frameworks of the implementation of health services. A framework can guide an organization in a strategic approach to implementation of an innovation.

Physical therapy practice strongly aligns with the comprehensive CFIR; however, many of the constructs did not surface through this qualitative study. In some cases, lack of support for constructs starkly contrasts with aspects of professional identity and organizational approaches to implementation. For example, quality of evidence, particularly research findings, was absent from innovation sources. Furthermore, intentional implementation efforts of management including designation of champions or leaders, and allocation of resources, did not surface within the data. The lack of verification of some of the constructs should not be interpreted as irrelevance, disagreement, or inaccuracy; rather, these constructs may require further investigation to determine applicability to a PT context.

While the implementation constructs are defined within domains, the practice change model ${ }^{10}$ suggests the interaction between constructs. In addition to construct verification, interplay among the characteristics of the innovation, individuals, and inner and outer settings reinforce, moderate, and/or weaken the organization's innovation capacity. For example, an individual's level of self-efficacy affects the innovation reinvention and trialability. Likewise, allocation of implementation resources is not likely to be sufficient 
support of an innovation that conflicts with organizational culture and values.

These smaller-sized clinics relied on decentralized control. Control was flexible in patient-care directives but more centralized in administrative directives such as billing, documentation, pay, and benefits. Both clinics were highly attentive to the external climate. The strength of alignment to CFIR constructs is likely varied in physical therapy practices with different sizes, ownership structures, and cultures.

Findings of this study strongly support appreciation of practice innovation as a social phenomenon. Adaptive practice occurred through a dynamic, social process of peer referencing of practice behaviors. Studies have described distinct inclinations in social networks within particular professions. For example, nursing tends to have formal, vertical networks, whereas physicians tend to have informal, horizontal networks. ${ }^{34}$ This study is not of sufficient breadth to make generalization on the typical social network structure within the physical therapy profession, but these small practices were inclined toward horizontal networks. Furthermore, the communication networks within these practices followed typical DOI patterns that rely on interpersonal connections.

Connections, or ties, among individuals can be characterized on a continuum of strong to weak based on the duration of personal contact and the intimacy and reciprocal nature of the relationship. Strong ties tend to exchange redundant information; therefore, transmission of information through a social group is largely conveyed through weak ties as these sources are more likely to present novel information. ${ }^{35}$ Figure 3 presents a theoretical representation of the clustered, clinical communication network. Burt ${ }^{37}$ has described the social capital of individuals who can effectively span groups.
Creativity and good ideas are a product of exposure to ideas that depart from one's homogeneous group. These individuals with tolerance of uncertainty and challenged assumptions can fill the between-group "structural holes" improving an organization's performance.

The clinic owner who functions as the innovator has strong ties to outside influences who introduce innovation. The innovator relies on the change agent, the influential group member who has strong ties to both the innovator and networks within the clinic.

\section{Limitations}

This study focused on implementation that was occurring at the time of the investigator's contact. Although clinic experiences with previous implementation were included in the investigation, durability or confirmation of the innovations of interest was not included in the scope of this study.

This study took place in independent, small, outpatient physical therapy practices. It was the intent of the study to test DOI and implementation framework within smaller units of practice; however, this limits confirmation of constructs such as organizational size, complexity, and team implementation approaches. Further study of other contexts of physical therapy practice including larger practices and practices within healthcare systems or hospitals is needed.

Application of a qualitative directed content approach potentially imposes confirmation bias of factors presented in the CFIR guiding framework and constrains discovery or identification of factors unique to the PT context. ${ }^{31}$ This approach offers useful preliminary findings that warrant vetting through further rigorous qualitative and quantitative research.

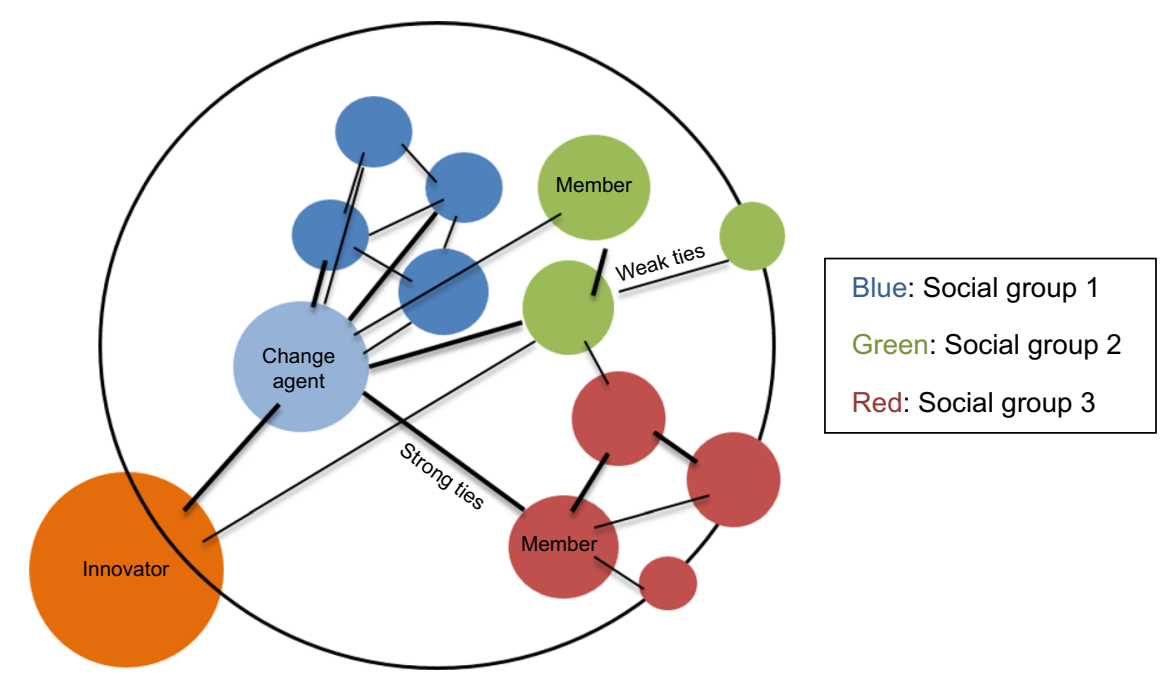

Figure 3 Communication networks.

Notes: Circle size represents individual level of influence. Line width indicates strength of tie. 


\section{Conclusion}

Innovation in outpatient physical therapy practice can be understood as a social process situated within the culture of the physical therapy professional. This study verified adoption of innovation that follows predictable patterns that largely match DOI theory and implementation science in health care services. Application of these findings requires consideration of the elements that are modifiable and acknowledgment of elements that are nonmodifiable. For example, an administrator implementing a significant clinical innovation cannot adjust the size of the organization or level of staff; however, implementation should consider capitalizing on information flow within established communication channels and allow opportunity for trial with the innovation that builds user confidence and self-efficacy.

Despite most PT's commitment to professional development and continuing education, habits of practice are difficult to adjust. This work offers an organizational perspective on practice innovation that may involve implementation of guidelines, adoption of an evidence-based intervention, or response to policy or regulation. The organizational dimensions of innovative physical therapy practice must be better understood by physical therapy managers and leaders who are involved in initiatives to achieve high-quality, progressive, EBP.

\section{Acknowledgments}

The authors acknowledge Kat McNally, DPT, University of Kansas Medical Center, and Dave McNiel, DPT, University of Kansas Medical Center, for their involvement in data analysis. This study was funded by a research grant of the Health Policy and Administration Section of the American Physical Therapy Association.

\section{Disclosure}

The authors report no conflicts of interest in this work.

\section{References}

1. Morris Z, Wooding S, Grant J. The answer is 17 years, what is the question: understanding time lags in translational research. J $R$ Soc Med. 2011;104(12):510-520.

2. Drolet B, Lorenzi N. Translational research: understanding the continuum from bench to bedside. Transl Res. 2011;157(1):1-5.

3. Cain M, Mittman R. Diffusion of Innovation in Health Care. Oakland, CA: California Healthcare Foundation; 2002.

4. Denis JL, Hebert Y, Langley A, Lozeau D, Trottier LH. Explaining diffusion patterns for complex health care innovations. Health Care Manage Rev. 2002;27(3):60.

5. Shirey MR. Evidence-based practice: how nurse leaders can facilitate innovation. Nurs Adm Q. 2006;30(3):252-265.

6. West M, Altink W. Innovation at work: Individual, group, organizational, and socio-historical perspectives. Eur J Work Organ Psychol. 1996;5(1):3-11.
7. Henriksen K, Battles J, Marks E, Lewin D. From Science to Service: A Framework for the Transfer of Patient Safety Research into Practice. Rockville, MD: Agency for Healthcare Research and Quality (US); 2005. Available from: http://www.ncbi.nlm.nih.gov/books/NBK20521. Accessed January 29, 2015.

8. May C, Finch T, Mair F, et al. Understanding the implementation of complex interventions in health care: the normalization process model. BMC Health Serv Res. 2007;7(1):148.

9. Lukas CVD, Holmes SK, Cohen AB, et al. Transformational change in health care systems: an organizational model. Health Care Manage Rev. 2007;32(4):309.

10. Cohen D, McDaniel RR Jr, Crabtree BF, et al. A practice change model for quality improvement in primary care practice. $J$ Healthc Manag. 2004;49(3):155-170.

11. Sanson-Fisher RW. Diffusion of innovation theory for clinical change. Med J Aust. 2004;180(6 Suppl):S55-S56.

12. Omachonu VK, Einspruch NG. Innovation in healthcare delivery systems: a conceptual framework. Innov J Public Sect Innov J. 2010;15(1):1-20.

13. Greenhalgh T, Robert G. Diffusion of innovations in service organizations: systematic review and recommendations. Milbank $Q$. 2004;82(4):581-629.

14. Rogers EM. Diffusion of Innovations. 5th ed. New York: Free Press; 2003.

15. Gladwell M. The Tipping Point: How Little Things Can Make a Big Difference. New York, NY: Little Brown; 2006.

16. Gosling AS, Westbrook JI, Braithwaite J. Clinical team functioning and IT innovation: a study of the diffusion of a point-of-care online evidence system. J Am Med Informatics Assoc. 2003;10(3):244-251.

17. Bobiak SN, Zyzanski SJ, Ruhe MC, et al. Measuring practice capacity for change: a tool for guiding quality improvement in primary care settings. Qual Manag Health Care. 2009;18(4):278-284.

18. McCluskey A, Lovarini M. Providing education on evidence-based practice improved knowledge but did not change behaviour: a before and after study. BMC Med Educ. 2005;5(1):40.

19. Hatala R, Guyatt G. Evaluating the teaching of evidence-based medicine. JAMA. 2002;288(9):1110-1112.

20. Hatala R, Keitz SA, Wilson MC, Guyatt G. Beyond journal clubs. Moving toward an integrated evidence-based medicine curriculum. $J$ Gen Intern Med. 2006;21(5):538-541.

21. Kawamoto K, Houlihan CA, Balas EA, Lobach DF. Improving clinical practice using clinical decision support systems: a systematic review of trials to identify features critical to success. BMJ. 2005;330(7494):765.

22. Coye M, Aubry W, Yu W. The "Tipping Point" and Health Care Innovations: Advancing the Adoption of Beneficial Technologies; 2003. Available from: http://www.nihcm.org/pdf/Coye.pdf. Accessed March $10,2015$.

23. Damschroder L, Aron D, Keith RE, Kirsh SR, Alexander JA, Lowery JC. Fostering implementation of health services research findings into practice: a consolidated framework for advancing implementation science. Implement Sci. 2009;4(1):50.

24. Schein E. Kurt Lewin's change theory in the field and in the classroom: notes toward a model of managed learning. Syst Pract. 1996;9(1): $27-47$.

25. Donaldson NE, Rutledge DN, Ashley J. Outcomes of adoption: measuring evidence uptake by individuals and organizations. Worldviews Evid Based Nurs. 2004;1(S1):S41-S52.

26. Godin G, Bélanger-Gravel A. Healthcare professionals' intentions and behaviours: a systematic review of studies based on social cognitive theories. Implement Sci. 2008;3(36):1-12.

27. Frambach R, Schillewaert N. Organizational innovation adoption: a multi-level framework of determinants and opportunities for future research. J Bus Res. 2002;55(2):163-176.

28. Inclusion Criteria for Health Care Policy Innovations [webpage on the Internet]. AHRQ Health Care Innovations Exchange; 2014. Available from: https://innovations.ahrq.gov/inclusion-policy. Accessed June 10, 2015 . 
29. Evertz J. Evaluating qualitative research. In: Munhall PL, editor. Nursing Research: A Qualitative Perspective. Sudbury, MA: Jones \& Bartlett Learning; 2001:599-612.

30. Horsburgh D. Evaluation of qualitative research. J Clin Nurs. 2003; 12(2):307-312.

31. Hsieh H-F, Shannon SE. Three approaches to qualitative content analysis. Qual Health Res. 2005;15(9):1277-1288.

32. Thomson O'Brien MA, Freemantle N, Oxman AD, Wolf F, Davis DA, Herrin J. Continuing education meetings and workshops: effects on professional practice and health care outcomes. Evid Based Nurs. 2002;5(1):26.
33. Rappolt S, Tassone M. How rehabilitation therapists gather, evaluate, and implement new knowledge. J Contin Educ Health Prof. 2002;22(3):170-180.

34. West E, Barron D, Dowsett J, Newton J. Hierarchies and cliques in the social networks of health care professionals: implications for the design of dissemination strategies. Soc Sci Med. 1999;48(5):633-636.

35. Granovetter M. The strength of weak ties. Am J Sociol. 1973;78(6): 1360-1380. Available from: http://www.jstor.org/stable/2776392. Accessed June 10, 2015.

36. Burt R. Structural holes and good ideas. Am J Sociol. 2004;110(2): 349-399. 


\section{Supplementary materials}

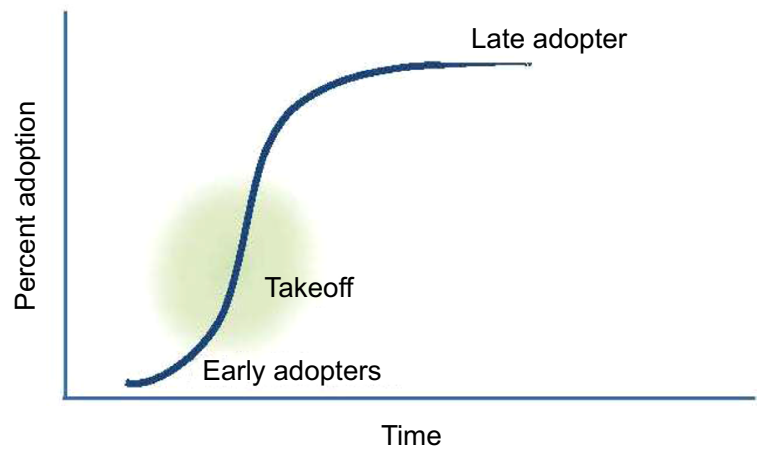

Figure SI Diffusion of Innovation Curve.

Table SI Member check feedback survey (indicate the degree that the following study findings seem true)

\begin{tabular}{|c|c|c|c|c|}
\hline Findings statement & $\begin{array}{l}\text { Very } \\
\text { accurate }\end{array}$ & $\begin{array}{l}\text { Somewhat } \\
\text { accurate }\end{array}$ & $\begin{array}{l}\text { Somewhat } \\
\text { inaccurate }\end{array}$ & $\begin{array}{l}\text { Very } \\
\text { inaccurate }\end{array}$ \\
\hline \multicolumn{5}{|l|}{$\begin{array}{l}\text { Change tends to be introduced by clinic members who are influenced by information } \\
\text { sources outside the clinic }\end{array}$} \\
\hline \multicolumn{5}{|l|}{$\begin{array}{l}\text { Physical therapists (PTs) in this clinic rely on comfortable networks of } \\
\text { communication to gain information and make meaning of changes }\end{array}$} \\
\hline \multicolumn{5}{|l|}{$\begin{array}{l}\text { The clinic has a general tolerance of change and is represented by those who identify } \\
\text { as progressive and innovative }\end{array}$} \\
\hline \multicolumn{5}{|l|}{$\begin{array}{l}\text { For change to be accepted in this clinic, it has to seem compatible with the current } \\
\text { clinic values and goals }\end{array}$} \\
\hline \multicolumn{5}{|l|}{$\begin{array}{l}\text { PTs in this clinic choose experimentation over mandates in the process of } \\
\text { implementing new things }\end{array}$} \\
\hline \multicolumn{5}{|l|}{ PTs in this clinic need tangible proof that change is needed and working } \\
\hline \multicolumn{5}{|l|}{$\begin{array}{l}\text { Any changes in this clinic must be grounded in the patient-centered care that we } \\
\text { provide }\end{array}$} \\
\hline \multicolumn{5}{|l|}{$\begin{array}{l}\text { Our clinic is always positioned for the next opportunity or to respond to the } \\
\text { next threat }\end{array}$} \\
\hline \multicolumn{5}{|l|}{$\begin{array}{l}\text { Our clinic's ability to change and survive makes the relationships among } \\
\text { staff stronger }\end{array}$} \\
\hline \multicolumn{5}{|l|}{ Comments: } \\
\hline \multicolumn{5}{|l|}{ I. Does a shared philosophy of care create a culture that makes changes easier or harder? } \\
\hline \multicolumn{5}{|l|}{ 2. In a clinic with staff who share a philosophy of care, how are new ideas best cultivated? } \\
\hline \multicolumn{5}{|c|}{ 3. To what degree does innovation flow both ways, with introduction of change from either within the clinic or outside? } \\
\hline 4. How does the process of change differ depending on where the idea comes from? & & & & \\
\hline
\end{tabular}

\section{Publish your work in this journal}

The Journal of Healthcare Leadership is an international, peer-reviewed, open access journal focusing on leadership for the health profession. The journal is committed to the rapid publication of research focusing on but not limited to: Healthcare policy and law; Theoretical and practical aspects healthcare delivery; Interactions between healthcare and society and evidence-based practices;

\section{Dovepress}

Interdisciplinary decision-making; Philosophical and ethical issues; Hazard management; Research and opinion for health leadership; Leadership assessment. The manuscript management system is completely online and includes a very quick and fair peer-review system. Visit http://www.dovepress.com testimonials.php to read real quotes from published authors. 